\title{
"Pregnant and Operating": Evaluation of a Germany-wide Survey Among Female Gynaecologists and Surgeons
}

\section{„Schwanger und Operieren“: Auswertung einer deutschlandweiten Erhebung unter Frauenärztinnen und Chirurginnen}

Authors

Affiliations
C. Knieper ${ }^{1}$, B. Ramsauer ${ }^{2}$, K. Hancke ${ }^{3}$, A. Woeckel $^{4}$, L. Ismail ${ }^{1}$, A. Bühren ${ }^{5}$, B. Toth

Gynecological Endocrinology and Fertility Disorders, Ruprecht-Karls University Heidelberg, Heidelberg

${ }^{2}$ Vivantes Hospital Neukölln, Berlin

${ }^{3}$ Department of Obstetrics and Gynecology, University Hospital, Ulm

${ }^{4}$ Department of Obstetrics and Gynecology, Julius Maximilians University Würzburg, Würzburg

${ }^{5}$ Medical Practice for Psychosomatic Medicine and Psychotherapy, Murnau

\section{Key words \\ - pregnancy \\ - operating nursing mothers \\ Schlüsselwörter \\ - Schwangerschaft \\ - Operieren \\ - Mutterschutz}

- protection of expectant and

Deutschsprachige Zusatzinformationen online abrufbar unter: www.thieme-connect.de/ ejournals/toc/gebfra

$\begin{array}{ll}\text { received } & 22.7 .2014 \\ \text { revised } & 21.8 .2014 \\ \text { accepted } & 21.8 .2014\end{array}$

Bibliography

DoI http://dx.doi.org/ 10.1055/s-0034-1383065

Geburtsh Frauenheilk 2014; 74: 875-880 @ Georg Thieme

Verlag KG Stuttgart · New York ISSN 0016-5751

\section{Correspondence}

Catherine Knieper

Universitätsfrauenklinik Heidelberg

Gynäkologische Endokrinologie und Fertilitätsstörungen

Im Neuenheimer Feld 440

69120 Heidelberg

knieperc@googlemail.com

\section{Abstract}

$\nabla$

The current law on the protection of expectant and nursing mothers largely rules out surgical activities during pregnancy for female doctors who perform surgical roles in hospitals. The proportion of female junior staff in gynaecology amounts to $80 \%$, and, for many of these women, surgical further training is not possible following official notification of an existing pregnancy. In a Germany-wide survey of female gynaecologists and surgeons using a questionnaire, it was determined to what extent female doctors worked in surgery during pregnancy, whether it led to complications in the pregnancy, when the employer was notified about the pregnancy, and what desire for change there is with regard to the law on the protection of expectant and nursing mothers. The data from 164 female doctors, of which 136 are gynaecologists and 28 surgeons, was evaluated. On average, the pregnancy was announced during the 14th week of pregnancy (WOP), and the doctor was not allowed to perform surgical activities in the 21st WOP. Female doctors in higher professional roles tended to announce the pregnancy later and ended their surgical activities later. There was no link between the time of ceasing surgical activities and an increased occurrence of complaints or complications during the pregnancy. In total, only $53 \%$ of respondents had an appraisal during pregnancy and $75 \%$ wanted a change in the law on the protection of expectant and nursing mothers.

\section{Introduction}

The law on the protection of expectant and nursing mothers (MuSchG) is based on the law to protect working mothers dated 24.1.1952 and has

\section{Zusammenfassung \\ $\nabla$}

Das aktuelle Mutterschutzgesetz schließt eine operative Tätigkeit während der Schwangerschaft für in der Klinik operativ tätige Ärztinnen weitestgehend aus. Der Anteil der Berufseinsteigerinnen liegt in der Gynäkologie bei $80 \%$, für viele dieser Frauen ist die operative Weiterbildung nach offizieller Mitteilung einer bestehenden Schwangerschaft nicht möglich. In einer deutschlandweiten Umfrage unter Gynäkologinnen und Chirurginnen wurde anhand eines Fragebogens u.a. ermittelt, inwieweit Ärztinnen in der Schwangerschaft operativ tätig waren, ob es zu Komplikationen in der Schwangerschaft kam, wann die Schwangerschaft dem Arbeitgeber mitgeteilt wurde und welche Änderungswünsche bez. des Mutterschutzgesetzes bestehen. Die Daten von 164 Ärztinnen, davon 136 Gynäkologinnen und 28 Chirurginnen, wurden ausgewertet. Die Schwangerschaft wurde im Mittel in der 14. Schwangerschaftswoche (SSW) bekanntgegeben, ein Ausschluss aus der operativen Tätigkeit erfolgte in der 21. SSW. Ärztinnen in höheren beruflichen Positionen gaben tendenziell später die Schwangerschaft bekannt und beendeten später die operative Tätigkeit. Es bestand kein Zusammenhang zwischen dem Zeitpunkt des Ausscheidens aus der operativen Tätigkeit und einem vermehrten Auftreten von Beschwerden oder Komplikationen während der Schwangerschaft. Insgesamt führten nur 53\% der Befragten in der Schwangerschaft ein Personalgespräch und 75\% wünschten sich eine Änderung des Mutterschutzgesetzes.

been revised numerous times since then, most recently in March 2009 (Article 14, BGBl. I, P. 550). In its current version, it largely restricts the possibilities of surgical activities for female gynaecologists and surgeons working in hospitals [1]. As a 
result, pregnant women may not work standing up for more than 4 hours after the 5 th month and there is an employment ban both between $8 \mathrm{pm}$ and $6 \mathrm{am}$ as well as on bank holidays. The handling of substances that pose a risk to health, such as anaesthetic gases, or cytostatics or radiation including $\mathrm{x}$-rays is not permitted. Both MuSchG and the act to protect women in the workplace (MuSchArbV) relate exclusively to women who are in an employment relationship. Neither female students nor doctors in their own surgeries are included in this. This, in turn, also means that the employed doctor may no longer work in surgery once the pregnancy is announced, but independent doctors may continue.

Many pregnant doctors are primarily entrusted with organisational and administrative tasks instead of specialist medical interventions once their pregnancy is announced [2]. Especially due to the exclusion from surgery, specialist medical training may be extended or the affected female doctor often falls behind in the hospital's internal ranking compared with her male colleagues $[3,4]$. This means that pregnancies are often only reported to the employer at a later stage. However, this should be viewed critically, especially in a surgical environment, as this may mean no institutional support is guaranteed in observing the necessary safety measures (e.g. collection of the relevant lab parameters before a surgical intervention, use of non-puncturing instruments, use of projectable interventions, duration of surgery a maximum of 4 hours, release from night shifts and no primary responsibility during emergencies) $[5,6]$. One should therefore aim at updating the legislation on the protection of expectant and nursing mothers so that pregnant doctors can also perform the surgery they would like to perform under the greatest possible safety standards with the support of the company doctor and hospital management.

On the other hand, there are female doctors with (high-risk) pregnancies who do not want to undertake any surgical activities and thus are afraid of changes to MuSchG. These must naturally be relieved of any potentially hazardous activities or any activities that conflict with their current situation in the pregnancy [7].

As part of our Germany-wide study, female gynaecologists and surgeons were asked about their experience with regard to surgical activities during pregnancy, obstetric complications, the time the pregnancy was announced and the desire for changes to MuSchG.

\section{Materials and Methods}

$\nabla$

\section{Data collection and questionnaire}

Dr. Astrid Bühren and Prof. Bettina Toth, members of the former "Career and Family" commission at German Society for Gynaecology and Obstetrics (Deutsche Gesellschaft für Gynäkologie und Geburtshilfe, DGGG) drafted the "pregnant and operating" questionnaire in 2011 and initially published it in Chirurgische Allgemeine Zeitung [1]. The questionnaire was then distributed to members of the DGGG online and at conferences (e.g. DAGG conference Berlin 2011, conference for perinatal medicine Berlin 2012, DGGG conference Munich 2012).

The following data was collected: current age, partnership, current professional position and the position during the (respective) pregnancy, the time the pregnancy was announced to the manager, and the time surgical activities were ceased, motivation with regard to surgical activities, the number of hours in surgery, physical complaints during surgical activities and complications during pregnancy, the time of childbirth and return to work. What's more, in the event of a premature birth, it was questioned whether there was a causal link to the surgical activity. It was ascertained whether the respondents would once again undertake surgery during the pregnancy, whether an appraisal was carried out and what desire there was for changes to MuschG.

\section{Statistical analysis}

The statistical assessment was performed using the statistics software $\mathrm{R}$ and the Review Manager, version 5.1 (Copenhagen, The Nordic Cochrane Centre, The Cochrane Collaboration, 2011). As part of an explorative data analysis, box plots and bar charts were created. A mean value analysis was performed using a twosample t-test and a single-factor analysis of variance (ANOVA). To analyse contexts, a chi-square test, Bravais-Pearson and Kendall's tau correlation coefficient were used along with the present scale of measure and the relative risk calculated. A p-value of $<0.05$ was determined as a significance level. If there was a p-value of $<0.1$, this was interpreted as an indicator of a link or weak significance. Data are expressed below as mean \pm standard deviation (minimum - maximum).

\section{Results}

$\nabla$

\section{Study population}

164 female doctors participated in the study, of which 136 were gynaecologists involved in surgery and 28 surgeons. The majority (73.2\%) were younger than 45 years, $26.8 \%$ were older than 45 years ( $\odot$ Fig. 1 ).

At the time of data collection, 49 respondents were undertaking specialist further training, 73 practiced as specialists, 28 as specialist registrars, 7 as leading specialist registrars and 6 as consultants.

The majority ( $82 \%$ ) were married, 3\% were in a relationship, $11 \%$ lived separately from their partner, $2 \%$ were divorced and $2 \%$ single mothers.

On average, the respondents had $2.05 \pm 1.0$ children (1-7).

\section{Operating and pregnancy}

The pregnancy was announced on average in the 14th WOP (13.8 \pm 5.5 [5-32]). Leading specialist registrars tended to inform their employer 5 weeks later than assistant doctors (19.2 WOP

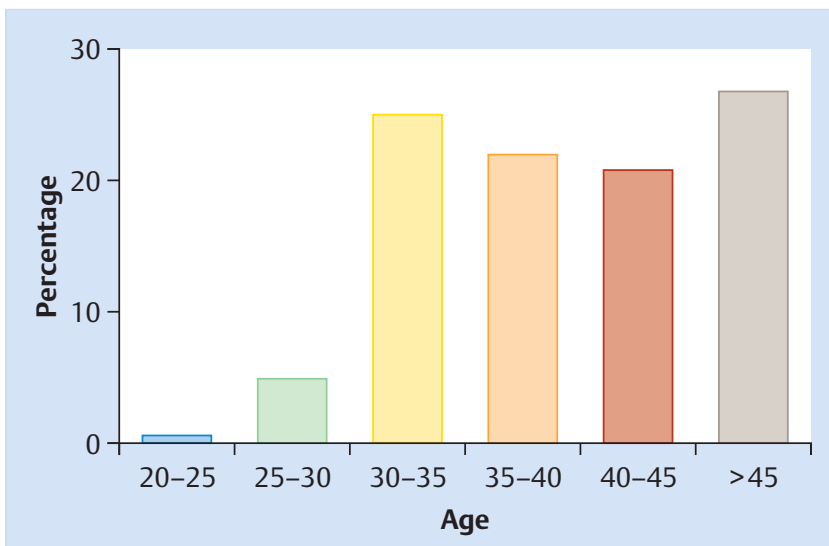

Fig. 1 Percentage age distribution according to age groups, $n=161$. 

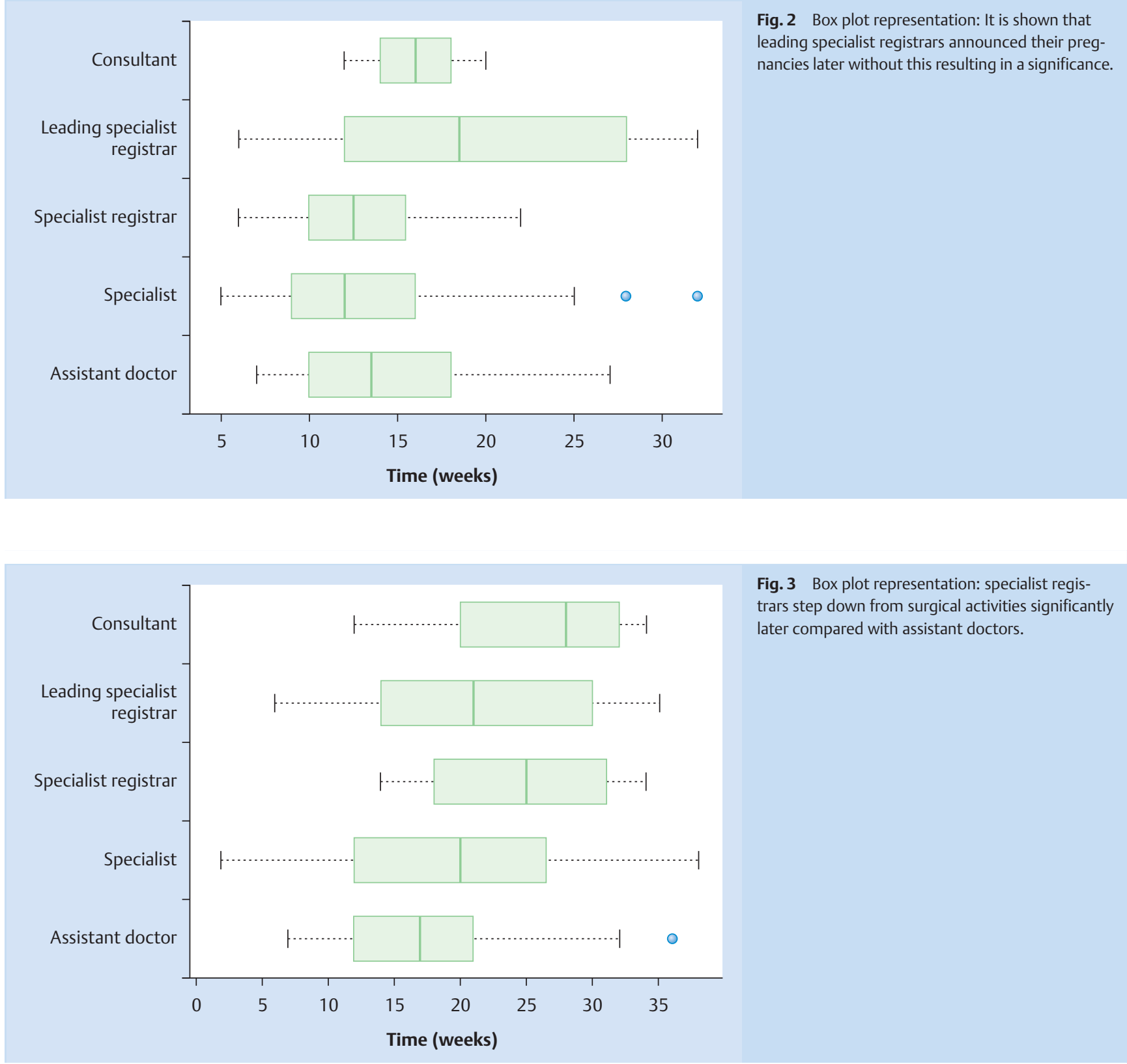

compared with 14.0 WOP). An ANOVA analysis resulted in no significance in the comparison of all professional groups ( $\bullet$ Fig. 2) and also a comparison of the younger ( $<45$ years) and older respondents ( $>45$ years) showed no significant difference in the time the pregnancy was announced.

On average, surgical activities were ceased in the 21st WOP (20.6 \pm 8.7 [2-38] WOP). There was found to be a trend towards ceasing surgical activities later in more elevated professional positions. In the direct comparison between assistant doctors and consultants, it was found that consultants ceased surgery significantly later (18.4 vs. 24.7 WOP, $\mathrm{p}=0.008$ ) ( Fig. 3). Younger respondents ( $<45$ years) also stepped down from surgical activities significantly earlier (19.4 vs. 24.7 WOP, p = 0.005).

The number of hours in surgery per day amounted on average to $4.0 \pm 2.8 \mathrm{~h}$ in the $1 \mathrm{st}$ trimester, $2.9 \pm 3.1 \mathrm{~h}$ in the $2 \mathrm{nd}$ trimester and $1.1 \pm 2.7 \mathrm{~h}$ in the 3rd trimester. Respondents with a higher number of hours in surgery ceased surgical activities at a later stage with a correlation coefficient $(r)$ of $0.22(p=0.03)$ and had their child significantly earlier $(\mathrm{r}=-0.21, \mathrm{p}=0.03)$.

\section{Complications and complaints}

Overall, $7.1 \%$ of the respondents had a premature birth, $2 \%$ (3/ 114) viewed this as a consequence of the surgical activities.

A correlation analysis produced no statistical link between the number of hours in surgery and complaints during the pregnancy, such as pelvic pain, increased illness, vaginal bleeding or premature contractions.

In the first pregnancy, $74.4 \%$ stated there were no complications, $2.9 \%$ stated foetal growth retardation, $2.9 \%$ a miscarriage, $7.1 \%$ a premature birth, $0.6 \%$ a premature rupture of the membranes and $0.6 \%$ other complications ( $\bullet$ Fig. 4 ).

There was no correlation between the time of stepping down from surgical activities and the occurrence of complications. There was also shown to be no significant link between the professional position and the occurrence of complications. 


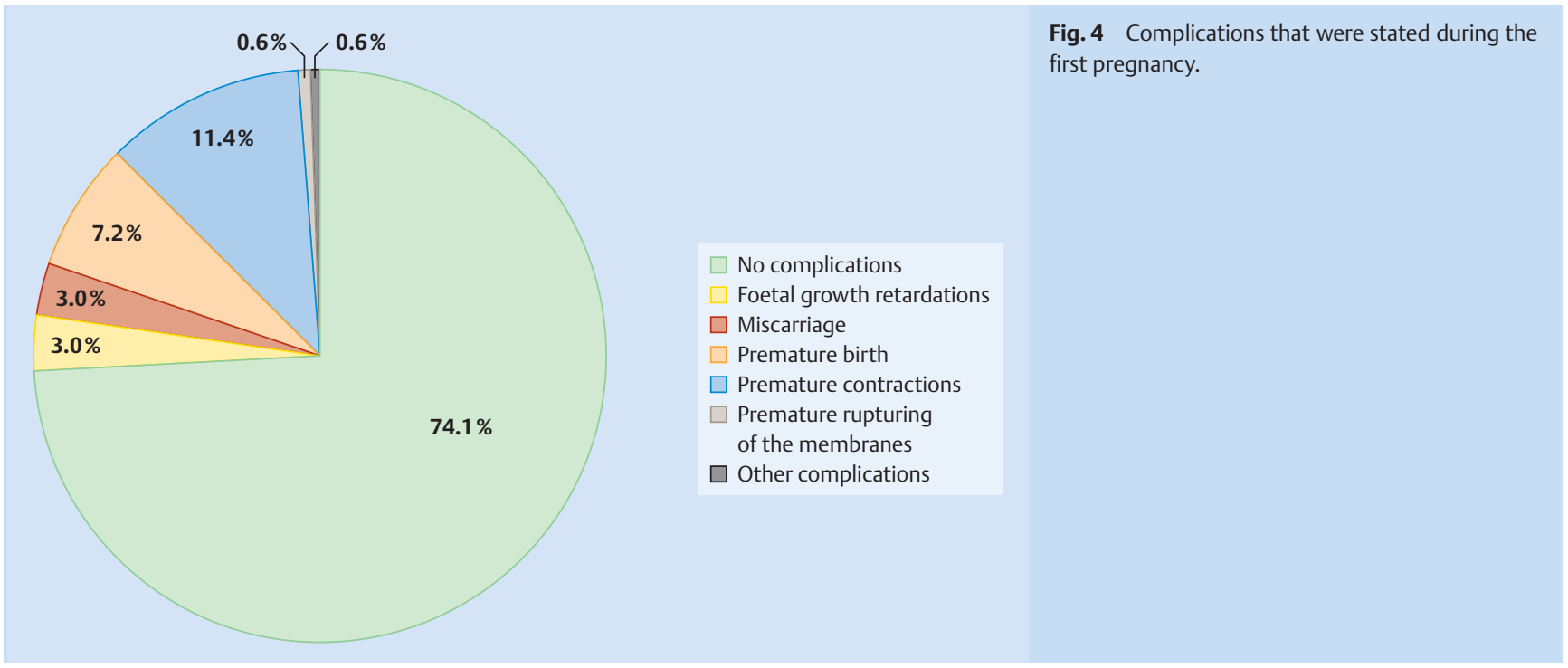

"There is no maternity protection in the office/in selfemployment. Maternity protection consisted of annual holiday and six weeks of free time. There needs to be protection against job losses during maternity protection."

"Possibility of making an individual decision about surgica activities in the form of an explicit 'positives list', which is permitted on request in order to facilitate the battle with administration."
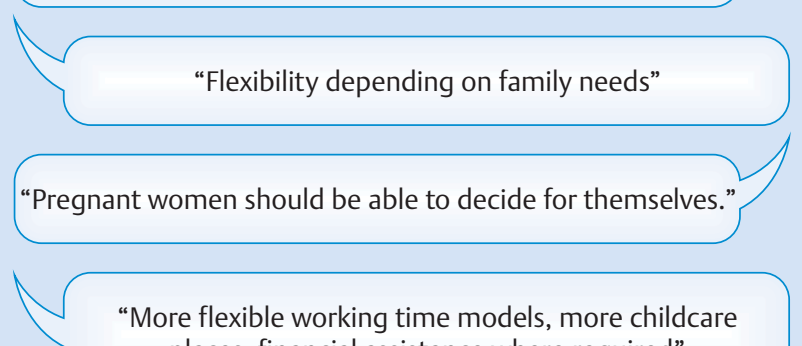
places, financial assistance where required"

"Off-setting of the time banned from surgery with an extension to further training"

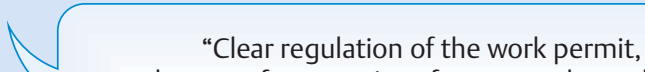
so there are fewer options for personal coordination by the employer."

"Less dishonesty. On the one hand, you're not allowed in surgery, but, on the other hand, you're exposed to secretions when taking blood and inserting intravenous cannulas. So you can continue performing surgery."

Fig. 5 Specific desire for change to MuSchG, which was entered on the form as side notes.

\section{Motivation and desire for change}

As motivation for surgical activities, the majority (88\%) stated their own preference, $8 \%$ "because of the manager", and $4 \%$ "because of colleagues".

Following the first pregnancy, the doctors returned to work after an average of $10.2 \pm 7.0$ months. $78 \%$ stated that they wanted to operate again after the pregnancy, $22 \%$ declined this.

Only in $53 \%$ of cases was an appraisal conducted as part of the pregnancy.

$75 \%$ of the respondents stated a desire for changes to be made to MuSchG. There was a significant trend among pregnant women performing surgery for a change to MuSchG $(\mathrm{p}=0.008)$. In total, $80 \%$ wanted the opportunity to make an individual decision on continuing surgical activities, $53 \%$ an established conversation about pregnancy and parental leave in accordance with the Heidelberg Pregnancy and Parental Leave programme (HeiSEP), and $49 \%$ wanted recognition of protection of expectant and nursing mothers for further training ( $\mathbf{0}$ Fig. $\mathbf{5}$ ).

\section{Discussion}

In the present Germany-wide survey among female gynaecologists and surgeons, it was possible to show that the majority of female doctors working in surgery want to undertake surgical activities voluntarily beyond the 14th WOP, although this is not possible due to the current MuSchG.

In total, questionnaires were assessed from 164 female gynaecologists and surgeons. On average, the respondents had 2.05 children. This roughly corresponds to the German average of 2.1 children among families with children (as of 2010) [8]. If one views the entirety of women in Germany (women with and without children), the average number of children per woman in 2010 came to $1.4-1.5$ [8]. At the same time, in $201033 \%$ of all female doctors and pharmacists were childless in comparison with $24 \%$ of the women in all professional groups.

In Germany, women are on average 29.2 years old when their 1 st child is born and there is the highest number of births in the age range between 30-34 years. Specialist further training, and thus the most intensive professional period, particularly in a surgical field, takes place in precisely this period [9]. The age at the time 
of delivery was not collected on the questionnaire, only the age at the time of the survey, whereby $75 \%$ of the women who responded were $<45$ years. In an American study of 100 female surgeons, it was found that a pregnancy is often delayed or even completely negated when working in a surgical field. Female surgeons with children stated that "children and family" had tended to hinder their careers [10]. Women without children earned 95\% of the salary of their male colleagues, while the percentage was just $75 \%$ for women with children [10]. As only women with children responded in our study due to the focus on "pregnant and operating", it is not possible to make a comparison here with childless female gynaecologists who work in surgery and female surgeons.

On average, the pregnancy was announced during the 14th WOP and surgical activities were ceased in the 21st WOP. On average, the respondents could thus continue operating for 7 weeks after the pregnancy was announced. However, younger respondents ( $<45$ years) ceased surgical activities significantly earlier (19 vs. 25 WOP). It is therefore conceivable that the on average significantly long surgical period (up to $21 \mathrm{WOP}$ ) is caused by the older respondents. However, the sample is too small for more detailed analyses of the respective sub-groups in relation to age and educational status.

Leading specialist registrars informed their employer about the pregnancy later than assistant doctors. Accordingly, women in higher positions also tended to end their surgical activities later. However, there was no significant link between the professional position and the occurrence of complications during the pregnancy.

There was found to be a correlation between the number of weekly hours in surgery and the time surgical activities were ceased. Women who performed surgery frequently also pursued this activity for longer overall, as expected.

Conversely, there was a negative correlation between the number of hours in surgery and the time of birth. Women who operated for a long time tended to have children at an earlier stage, although only $2 \%$ (3/114) stated a link between the occurrence of a premature birth and the surgical activities. However, there was no statistical link between the number of hours in surgery and the occurrence of complaints and complications. To our knowledge, there have so far not been any studies into the occurrence of complications including premature births among female doctors who work in surgery. If one compares the stated complications with the normal population, the incidence tends to be low. According to the current literature, the average risk of foetal growth retardation is $8.9 \%$ [11], of a miscarriage $12-31 \%$ [12], of a premature birth 5-7\% [13] and of the occurrence of a premature rupture of the membranes $2.9-3.5 \%$ [14].

Most of the respondents (75\%) wanted a change to MuSchG, especially the pregnant women who worked in surgery. There is obviously clear motivation, despite pregnancy, to continue working in surgery, as this decision in $88 \%$ of cases was made by the women themselves. However, it should be considered here that the women who completed the questionnaire may be a committed and select clientele and, due to the overall small number of female gynaecologists and surgeons who responded, no ultimate conclusion can be made with regard to all female doctors who work in surgery.

Overall, $78 \%$ of the respondents returned to surgical activities following the pregnancy. To our knowledge, there have so far not been any studies into the frequency of resuming surgical activities after pregnancy. However, it has already been described that

\section{Checklist for appraisal}

$\square$ Age during pregnancy

$\square$ Due date

$\square$ Start of protection for expectant and nursing mothers

$\square$ Remaining annual leave

$\square$ Overtime

$\square$ Anticipated start of absence

$\square$ Clarifications of provisions on the protection of expectant and nursing mothers

$\square$ Offer to analyse the personal risk situation for the pregnant member of staff

$\square$ Clarification of job-specific risks and exposure (avoidance of standing for prolonged periods of time, particular risk of infections with hepatitis B/C, HIV, CMV, parvovirus B19, etc.)

$\square$ Updating of the log book

$\square$ Elaboration of an individual professional curriculum for the pregnancy

$\square$ Drafting of a 5-year plan or presentation/ discussion of the individual career plan

$\square$ Presentation of individual risks as part of the pregnancy

Fig. 6 Checklist that is discussed with the manager as part of 3 appraisals [16].

female surgeons interrupt their university careers twice as often as male colleagues in order to take care of raising their children [15].

Only around half of the respondents (53\%) had an appraisal during pregnancy, although the majority (53\%) explicitly wanted such a meeting. There is a clear starting point here for improvements in the specific and individual implementation of MuSchG. HeiSEP offers one example ( $\bullet$ Fig. 6 ). As part of 3 appraisals, the rights and opportunities of the pregnant member of staff are determined with regard to the following points: integration into the hospital, the continuation and further development of academic activity, the designing of teaching, specialist further training and reintegration following parental leave or the protection of expectant and nursing mothers [16]. In this way, the activity during the pregnancy and after maternity leave is to be governed while taking into account the fear of announcing a pregnancy and thus the potential risks that it involves.

An approach chosen in other areas is, for instance, to create a "positives list" in which the possible activities during the pregnancy are set down. The Professional Association of German Anaesthetists (Berufsverband deutscher Anästhesisten, bda) published such a list for possible areas in which pregnant female anaesthetists and intensive care doctors work [17]. The Junge Forum of the German Society for Orthopaedics and Trauma Surgery (Deutsche Gesellschaft für Orthopädie und Unfallchirurgie, DGOU) is planning the publication of a policy document by 2015 with recommendations for action and an overview of the legal and data situation [18]. For pregnant gynaecologists, besides shorter operations, a rotation in sonography with an improvement in the DEGUM classification would be a feasible area of employment.

Encouragement following maternity leave is certainly also crucial. Here, mothers should be given the opportunity to brush up on any activities that have been "neglected" during pregnancy. 
Surgical activities are explicitly included in this. Against the backdrop of an increasing feminisation of the field of gynaecology with a female proportion of junior staff of $84.2 \%$ according to a recent survey [19], it is necessary that women with children also have the opportunity to continue their careers in hospital. Only in this way can the maintenance of care structures be guaranteed over the long term [20].

In summary, it was shown that, in particular, women who work in surgery would like MuSchG to be updated. This should take place on the basis of amended safety standards, scientific knowledge and an adaptation to other laws, such as the General Equal Treatment Act (Allgemeines Gleichbehandlungsgesetz, AGG). The decision to undertake surgical activities during pregnancy was made by the women themselves and did not lead to increased obstetric complications.

As, on the other hand, there are also colleagues who are concerned about a relaxing of MuSchG and fear its interpretation by colleagues or superiors, it is of key importance that an individual interpretation of MuSchG is possible so that pregnant women continue to be protected but are not restricted in their voluntary wish to undertake surgical activities or professional development.

\section{Conflict of Interest}

$\nabla$

None.

\section{References}

1 Bühren A. Mutterschutz Ja - Berufsverbot Nein. Chirurg BDC 2010; 10 : 533-536

2 Turner PL, Lumpkins K et al. Pregnancy among women surgeons. Arch Surg 2012; 147: 474-479

3 Hancke K, Igl W, Toth B. Work-life balance of German gynecologists: a web-based survey on satisfaction with work and private life. Arch Gynecol Obstet 2014; 289: 123-129

4 Hancke K, Toth B, Igl W et al. Career and family - Are they compatible? Geburtsh Frauenheilk 2012; 72: 403-407
5 Enders G. Infektionsgefährdung: Mutterschutz im Krankenhaus. Arbeitsmed Sozialmed Umweltmed 2003; 38: 324-335

6 Wicker S, Rabenau HF, Haberl AE et al. Blutübertragbare Infektionen und die schwangere Mitarbeiterin im Gesundheitswesen. Der Chirurg 2012; 83: 136-142

7 Struck J. Mutterschutzregelungen in Deutschland. XX 2012; 1: 80-85

8 Statistisches Bundesamt. Geburten in Deutschland. 2012. Online: https://http://www.destatis.de/DE/Publikationen/Thematisch/Bevoelkerung/Bevoelkerungsbewegung/BroschuereGeburtenDeutschland0120007129004.pdf?_blob=publicationFile; last access: 2014

9 Cydulka RK, D'Onofrio G, Schneider $S$ et al. Women in academic emergency medicine. Acad Emerg Med 2000; 7: 999-1007

10 Mayer KL, Ho HS, Goodnight JE jr. Childbearing and child care in surgery. Arch Surg 2001; 136: 649-655

11 Gaudineau A. [Prevalence, risk factors, maternal and fetal morbidity and mortality of intrauterine growth restriction and small-for-gestational age]. J Gynecol Obstet Biol Reprod (Paris) 2013; 42: 895-910

12 Thomas VV, Knight R, Haswell SJ et al. Maternal hair selenium levels as a possible long-term nutritional indicator of recurrent pregnancy loss. BMC Womens Health 2013; 13: 40

13 Beck S, Wojdyla D, Say L et al. The worldwide incidence of preterm birth: a systematic review of maternal mortality and morbidity. Bull World Health Org 2010; 88: 31-38

14 Chmaj-Wierzchowska K, Pięta B, Buks J et al. Determinants of favourable neonatal outcome after premature rupture of membranes (PROM) before 24 weeks of pregnancy-review of the literature and a case report. Ann Agric Environ Med 2012; 19: 577-580

15 Schroen AT, Brownstein MR, Sheldon GF. Women in academic general surgery. Acad Med 2004; 79: 310-318

16 Toth B, Schütz F, Sohn C. Das Heidelberger Schwangerschafts- und Elternzeitprogramm (HeiSep). Frauenarzt 2011; 52: 849-851

17 Hagemann $H$, Bühren A, Weis E et al. Mutterschutz in Anästhesiologie und Intensivmedizin. Anästhesiologie und Intensivmedizin 2014; 3 : 133-142

18 Niethard H. Positionspapier Operieren in der Schwangerschaft. 25.06.2014 16.08.2014. Online: http://www.jf-ou.de/?p=618; last access: 2014

19 Riepen T, Möbus V, Kullmer $U$ et al. Male and female physicians in hospital gynaecology departments - analysis of the impact of "Feminisation" from the viewpoint of medical directors. Geburtsh Frauenheilk 2013; 73: 53-58

20 Scheele F, Novak Z, Vetter K et al. Obstetrics and gynaecology training in Europe needs a next step. Eur J Obstet Gynecol Reprod Biol 2014; DOI: 10.1016/j.ejogrb.2014.04.014 